\title{
Comparative Encapsulation Efficiency of Lutein in Micelles Synthesized via Batch and High Throughput Methods
}

This article was published in the following Dove Press journal: International Journal of Nanomedicine

\author{
Lauren E Cosby' \\ Kil Ho Lee $\mathbb{D}^{2}$ \\ Thomas J Knobloch $\mathbb{D}^{3}$ \\ Christopher M Weghorst $\mathbb{D}^{3}$ \\ Jessica O Winter $\mathbb{D}^{1,2}$ \\ 'Biomedical Engineering, The Ohio State \\ University, Columbus, OH 43210, USA; \\ ${ }^{2}$ William G. Lowrie Department of \\ Chemical and Biomolecular Engineering, \\ The Ohio State University, Columbus, \\ $\mathrm{OH} 43210$, USA; ${ }^{3}$ College of Public \\ Health, Division of Environmental Health \\ Sciences, The Ohio State University, \\ Columbus, $\mathrm{OH} 43210$, USA
}

Correspondence: Jessica O Winter

Tel +I 6142477668

Email winter.63@osu.edu
Purpose: Black raspberries (BRBs) and their anthocyanin-rich hydrophilic fractions (BRB$\mathrm{H})$ have exhibited significant chemopreventative activity across aerodigestive cancers. Lutein, the primary component of the BRB lipophilic fraction (BRB-L), also demonstrates bioactivity potential, but is less well characterized, in part because of its poor, innate bioavailability. For these lipophilic compounds to be accurately evaluated for anticancer efficacy, it is necessary to increase their functional bioavailability using delivery vehicles Lutein has been delivered in commercial settings in emulsion form. However, emulsions are unstable, particularly in the gastrointestinal tract, which limit their use as an oral nutraceutical. Here, we evaluated lutein encapsulation and cellular uptake for nanoparticle (NP) delivery vehicles composed of three different materials synthesized via two different approaches.

Methods: Specifically, NPs were synthesized via smaller scale batch interfacial instability (II) sonication and semi-continuous high throughput electrohydrodynamic-mediated mixing nanoprecipitation (EM-NP) methods using polystyrene-polyethylene oxide (PSPEO) or polycaprolactone-polyethylene glycol (PCLPEG) block copolymers and PHOSPHOLIPON 90G ${ }^{\circledR}$ (P90G, Lipoid GmbH) lipids. Size distribution, lutein encapsulation efficiency (EE), and cellular uptake and delivery were evaluated for each NP formulation.

Results: NPs produced via high throughput EM-NP had higher EEs than NPs produced via batch II sonication, and P90G had the greatest EE (55\%) and elicited faster cellular uptake in premalignant oral epithelial cells (SCC83) compared to other delivery systems.

Conclusion: These qualities suggest P90G could be a beneficial candidate for future lutein in vitro delivery research and clinical translation for oral cancer prevention.

Keywords: black raspberries, lutein, oral cancer, scalable nanomanufacturing, nanoprecipitation, emulsification

\section{Introduction}

Lutein is a plant-derived, lipophilic, bioactive compound in the carotenoid phytochemical family, commonly found in a variety of fruits, including black raspberries and leafy green vegetables. ${ }^{1}$ Epidemiological studies show a strong correlation between fruit and vegetable intake, lutein, and positive health outcomes. ${ }^{2-5}$ Lutein is associated with reducing the risk of cardiovascular disease, age related macular degeneration, and certain cancers. ${ }^{5}$ Because it is derived from natural food sources, lutein is a particularly attractive compound for oral cancer prevention and treatment (ie, nutraceutical formulation). Lutein has several anticancer properties. It 
demonstrates antioxidant activity, including the ability to scavenge harmful free radicals, eliciting a protective effect against deoxyribonucleic acid (DNA) and cellular damage. $^{6}$ Lutein reduces cell proliferation, ${ }^{7,8}$ modifies gene expression, ${ }^{6,8}$ reduces cancer cell viability, and elicits an apoptotic effect. ${ }^{7}$ Black raspberries are one possible source of lutein and have independently exhibited chemopreventive properties in a number of aerodigestive malignancies, including oral cancer. ${ }^{9-11}$ However, because lutein is hydrophobic in nature, it exhibits poor bioavailability and bioaccessibility following oral consumption. To evaluate potential health benefits of black raspberries and lutein as chemopreventives for oral cancers, additional strategies are needed to enhance delivery.

Lutein consists of a long hydrocarbon chain with eight double bonds; hexene rings anchor each end of the hydrocarbon chain (Figure 1). These double bonds and terminal hydroxyl groups make lutein highly susceptible to degradation by light, heat, or oxidation. ${ }^{12,13}$ Oil-in-water emulsions can protect lutein against this degradation, ${ }^{14}$ and many researchers have examined lutein in emulsion form. ${ }^{14-18}$ Commercially, lutein nutritional supplements are available in capsule form, most typically as an oil emulsion for oral consumption. Despite their widespread use, there are several disadvantages of lutein delivery via emulsions. Emulsions have poor thermodynamic stability that can result in coalescence and phase separation; ${ }^{19}$ temperature, $\mathrm{pH}$, and freeze-thaw cycle sensitivity; ${ }^{15}$ Ostwald ripening; ${ }^{20}$ and lipid oxidation. ${ }^{21}$ Additionally, upon reaching the stomach, emulsion integrity is compromised by the low $\mathrm{pH}$ and proteolytic environment; sustained release is unachievable. As a result of these factors, lutein experiences chemical instability, short shelf life, and minimized bioavailability. The main approach to overcome these issues has been to stabilize emulsions through interfacial barriers that prevent coalescence, ${ }^{22}$ including the use of surfactants such as Tween 20/80 and sodium dodecyl sulfate, ${ }^{19}$ phospholipids, ${ }^{23}$ and biopolymers, ranging from proteins to polysaccharides. $^{22}$
One possible alternative is formulation in polymer/lipid micelles or nanoparticles, which are commonly employed for delivery of hydrophobic compounds. ${ }^{24,25}$ For example, polymer nanoparticles synthesized via the flash nano-precipitation (FNP) process of Prud'homme ${ }^{26}$ have been shown to result in very high encapsulation efficiencies of hydrophobic cargoes, exceeding those of standard sonication approaches. We have achieved similar successes through electrohydrodynamic mixing-mediated nanoprecipitation (EM-NP), ${ }^{27}$ which is based on FNP processes but does not require impinging jet flows at high Reynolds numbers common to most FNP approaches. ${ }^{28}$ EM-NP employs a water-miscible organic fluid (nonconductive) solvating amphiphiles and hydrophobic encapsulates that is delivered via an insulated, electrified, needle immersed in aqueous fluid (conductive). ${ }^{27}$ Applying high voltage to the needle creates an electric potential between the tip of the needle and a grounding electrode, inducing electrohydrodynamic (EHD) flow. This effect induces the rapid mixing needed to generate uniform particles via nanoprecipitation of the hydrophobic cargo that are stabilized by amphiphilic block copolymers (BCPs). Unlike the conventional FNP process, rapid mixing depends on the applied voltage instead of the flow rates employed. Hence, EM-NP is an attractive option for synthesizing vehicles encapsulating high-value therapeutics with the potential for high controllability over material processing. However, this approach has not previously been used to encapsulate bioactive compounds. Further, there are a wide variety of choices for delivery vehicles and predicting encapsulation efficiency based on drug/carrier chemical structures can be challenging. Encapsulation efficiencies can thus vary widely based on the process and the compounds employed. $^{29-32}$

To address some of these concerns, we evaluated the effect of synthesis method and delivery vehicle chemical composition on NP structure, lutein encapsulation, and resultant cellular uptake. NPs were synthesized using scalable EM-NP and batch sonication methods, which permitted comparison of chemical compatibility trends

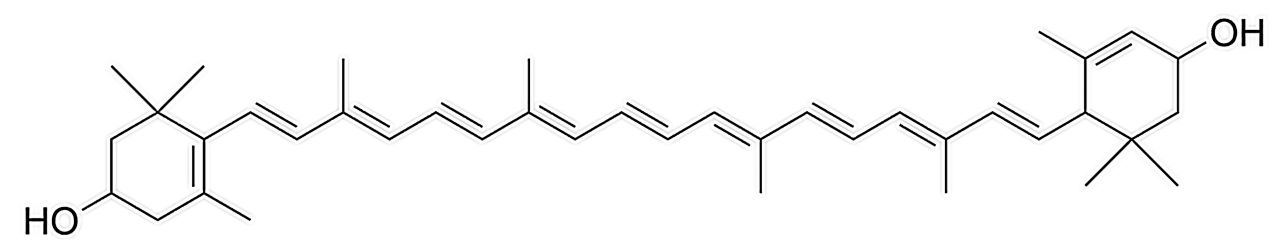

Figure I Chemical structure of lutein. 
across two different manufacturing platforms. Batch sonication was performed using the interfacial instability (II) method of Hayward, ${ }^{33}$ which has been identified as a thermodynamically-limited process, whereas EM-NP provides a kinetically-limited high throughput alternative. ${ }^{27}$ NP delivery vehicles were synthesized using three materials to provide a variety of drug-carrier compatibilities. Poly (styrene)-poly (ethylene oxide) (PSPEO) and poly (caprolactone)-poly (ethylene oxide) (PCLPEO) block copolymers were employed because they have previously been evaluated as drug delivery vehicles for hydrophobic cargoes in scalable nanoprecipitation processes. ${ }^{34,35}$ These materials were chosen for their biocompatibility, established characterization techniques, enhanced encapsulation abilities, and sustained release dynamics. ${ }^{29}$ As a comparison, we also analyzed PHOSPHOLIPON 90G (P90G), which has been previously used for oral delivery of poorly soluble compounds in preclinical studies, ${ }^{36-38}$ but which has not previously been employed in scalable processes. P90G is an FDA-approved, commercially-available, amphiphilic lipid (unsaturated diacyl-phosphatidylcholine) derived from soybean fatty acids (Figure 2). ${ }^{39}$ Because P90G is derived from natural, renewable sources, it is non-toxic, biodegradable and generally regarded as safe (GRAS); therefore, it is commonly used in pharmaceutical, oral and cosmetic delivery and formulation. Its polar head group and hydrocarbon chains mimic lipid structures found in the cellular membrane, allowing for enhanced cell incorporation, which also aids in gastrointestinal tract uptake and reduces gastric irritation commonly found with excipients. ${ }^{40}$ For each carrier, we evaluated the effect of synthesis technique on size and distribution, lutein encapsulation, and uptake in premalignant oral cancer cells. Thus, this work sets the stage for potential future study and use of lutein as a preventive agent for oral cancer and provides some preliminary guidance on potential approaches to predict drug encapsulation efficiency trends based on chemical compatibilities.

\section{Materials and Methods \\ Materials}

Carboxyl-terminated polystyrene-b-polyethylene oxide (PS-b-PEO-COOH, 9500-b-18,000 Da) and poly ( $\varepsilon$-caprolactone)-b-polyethylene oxide (PCL-b-PEO-COOH, 6000b-5000 Da) BCPs were used for micelle synthesis. PS-bPEO and PCL-b-PEO were obtained from Polymer Source Inc. (cat. no. P5755-SEOCOOH and P3130-EOCL, respectively). Lipid micelles were formed using a commercial phospholipid, PHOSHPOLIPON 90G (P90G) obtained from Lipoid (PHOSPHOLIPID GmbH, item no. SA-L368202). Lutein (xanthophyll, cat. no. X6250), Coumarin 6 (cat. no. 442,631) (a fluorescent dye reporter), polyvinyl alcohol (PVA, cat. no. 363,170), and Tween 20 (T20, P1379) were purchased from Sigma Aldrich.

\section{Particle Synthesis}

\section{Interfacial Instability (II) Sonication}

Lipid or polymer in tetrahydrofuran (THF, Sigma Aldrich, cat. no.178810) $(200 \mu \mathrm{L}, 1 \mathrm{mg} / \mathrm{mL})$ was combined with 5 $\mu \mathrm{L}$ of lutein in THF $(1 \mathrm{mg} / \mathrm{mL}), 4 \mathrm{~mL}$ of PVA $(5 \mathrm{mg} / \mathrm{mL})$, and $4 \mathrm{~mL}$ MilliQ water and sonicated (Branson Sonifior 450) for 5 minutes at a constant duty cycle. In the interfacial instability process, PVA serves to alter the surface tension of emulsion droplets, promoting droplet fission. ${ }^{33}$ After sonication, the solution was transferred to an aluminum dish and placed on a rocker for three hours to allow solvent to evaporate. The solution was then purified via centrifugal filtration using a $15 \mathrm{~mL} 100 \mathrm{kDa}$ molecular

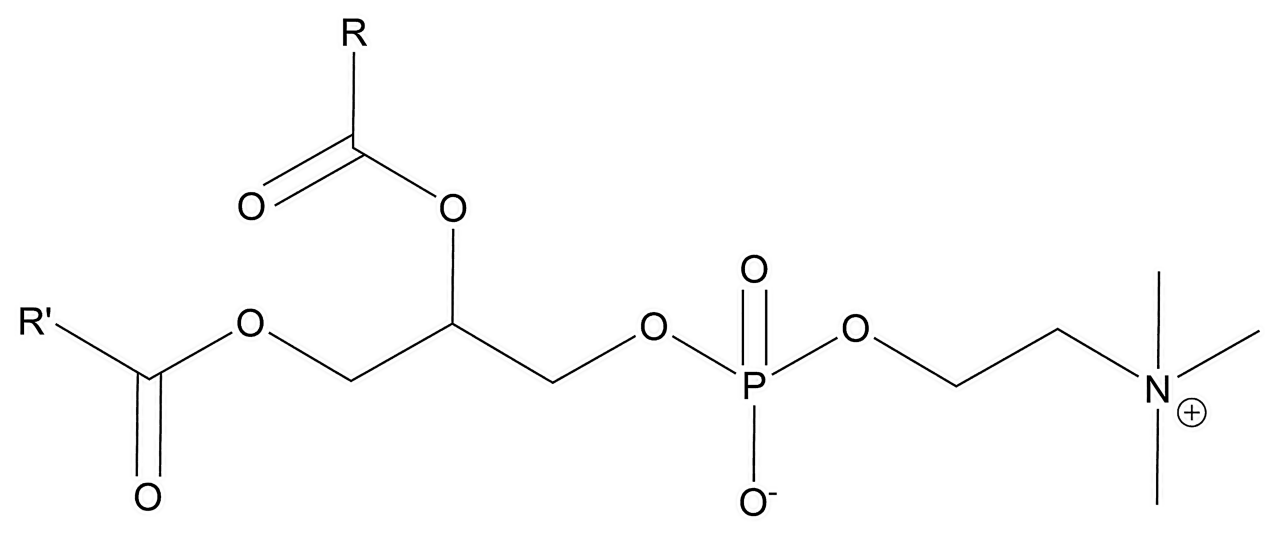

Figure 2 General structure of phosphatidylcholine, a constituent of P90G. 
weight cut-off (MWCO) centrifuge filter (Thermo Fisher, cat.no. UFC910096). Samples were washed three times with $3 \mathrm{~mL}$ MilliQ water for 15 minutes at $4000 \mathrm{rpm}$. Samples were then dried overnight via lyophilization for storage before further characterization.

\section{Electrohydrodynamic-Nanoprecipitation (EM-NP)}

Polymer $(200 \mu \mathrm{L}, 1 \mathrm{mg} / \mathrm{mL})$, lutein $(5 \mu \mathrm{L}, 1 \mathrm{mg} / \mathrm{mL})$, and Tween $20(20 \mu \mathrm{L}, 1 \mathrm{mg} / \mathrm{mL})$ in THF $(400 \mu \mathrm{L})$ were prepared prior to EM-NP (Figure 3) as the organic phase. ${ }^{27}$ An insulated needle delivering the organic phase via syringe pump was then inserted into the aqueous phase (ie, distilled deionized water). Then, a voltage was applied across the grounding electrode and the insulated needle, resulting in rapid electrohydrodynamic mixing of the aqueous phase, which led to atomization of the organic. Because the two phases are miscible, micelles formed nearly instantaneously via this approach. In this process, $200 \mu \mathrm{L}$ of organic was electrosprayed at $12.7 \mathrm{~mL} / \mathrm{hr}$ into $10 \mathrm{~mL}$ MilliQ water. After spraying, sample solutions were placed in aluminum dishes on a rocker for three hours to permit solvent evaporation. Samples were then purified as described above via centrifugal filtration and lyophilization.

\section{Particle Size and Morphology}

To characterize the size and shape of resultant NP micelles, negative stain consisting of $1 \%$ uranyl acetate $(20 \mu \mathrm{L})$ was applied for 5 minutes to samples mounted on carbon square copper 400 mesh grids (Fisher Scientific cat no. 5,024,891). Samples were then imaged using transmission electron microscopy (TEM, FEI Tecnai G2 Bio Twin). Images were analyzed using ImageJ software (NIH) to determine the Feret length, the measure of the longest axis, which, for spherical particles, is the diameter. Data were aggregated into bins ranging from 0 to $100 \mathrm{~nm}$, with widths of $10 \mathrm{~nm}$, normalized, and plotted as histograms to evaluate particle size distribution for each sample. Histogram plots were fitted using a three parameter logarithmic equation via SigmaPlot 14.0, as lognormal distribution is expected for drug-loaded micelles. ${ }^{41}$ Particle size mean, standard deviation, and polydispersity were determined using the following equations:

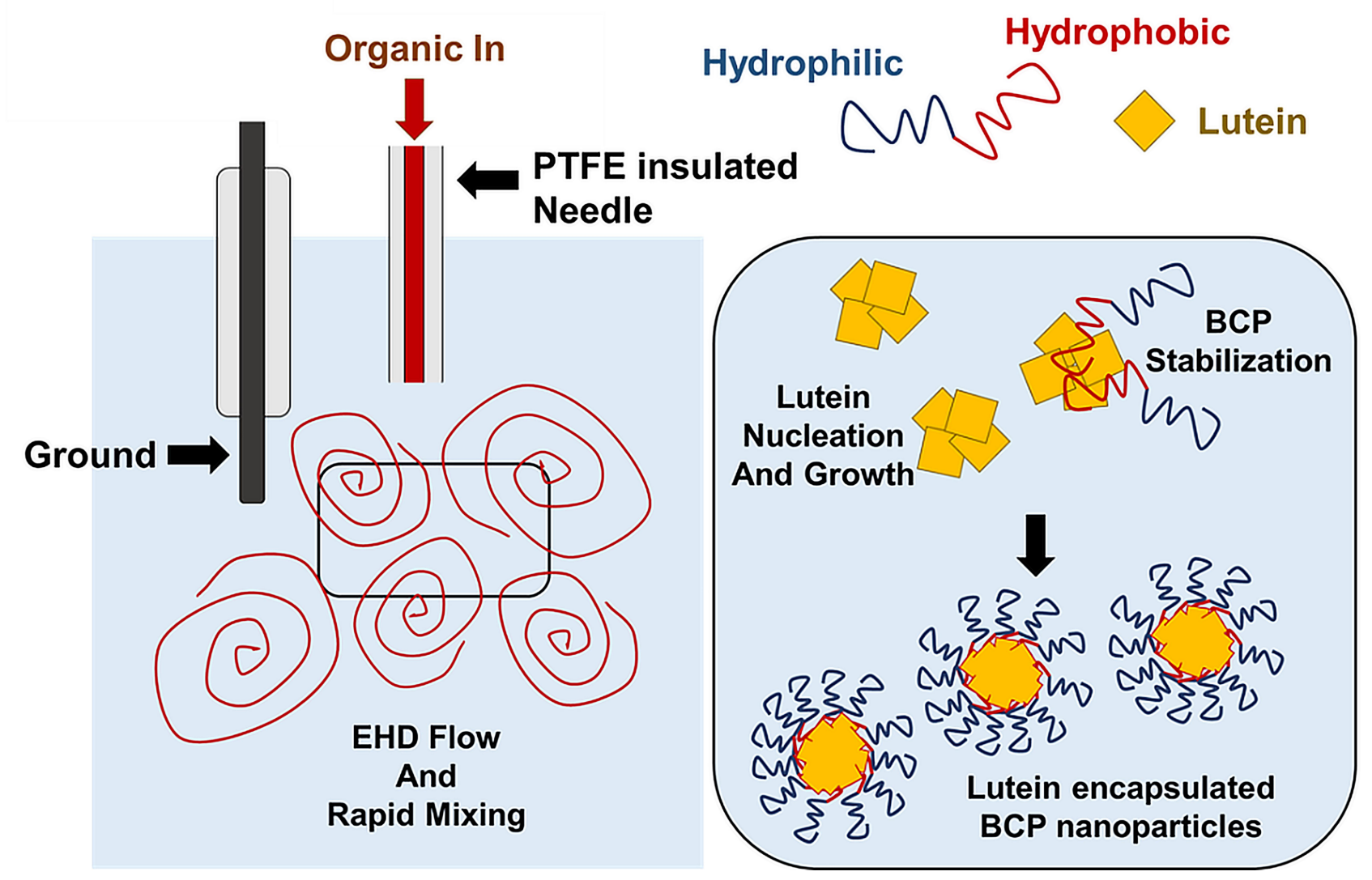

Figure 3 Schematic of EM-NP process. 


$$
\begin{gathered}
\mathrm{y}(\mathrm{x})=\frac{A}{x} e^{\left\{-0.5\left[\frac{\ln \left(\frac{x}{x_{0}}\right)}{b}\right]^{2}\right\}} \\
A=\frac{1}{\sqrt{2 \pi} b}
\end{gathered}
$$

Number mean $<x \geq e^{\left[\ln \left(x_{o}\right)+\left(\frac{b^{2}}{2}\right)\right]}$

Geometric standard deviation $(\sigma)=e^{b}$

$$
P D_{\text {eff }}=\frac{\sqrt{(-d e v)\left(+_{d e v}\right)}}{\langle\mathrm{x}\rangle}
$$

where $\mathrm{x}_{\mathrm{o}}$ and $\mathrm{b}$ are the median and the shape parameter, respectively, and PDeff are the effective polydispersity, and standard deviation on the - and + side of the distribution.

\section{Encapsulation Efficiency}

To measure encapsulation efficiency, lyophilized micelle samples were re-suspended in $300 \mu \mathrm{L} \mathrm{THF}$ and evaluated using UV-Vis (in a quartz cuvette) spectroscopy. Lutein has a signature peak at $450 \mathrm{~nm}$ in THF. ${ }^{42}$ Thus, a standard curve was generated and utilized to determine the final concentration of lutein in each sample $(\mu \mathrm{g} / \mathrm{mL}$ and total mass). The following equation was used to determine the percent encapsulation (ie, encapsulation efficiency, EE) for each particle system:

$$
E E=\frac{\text { Final Mass Lutein }(\mu g)}{\text { Initial Mass Lutein }(\mu g)} \times 100
$$

These results were compared to the Hansen solubility parameters for each system to estimate lutein and polymer interactions and to interpret trends in EE data. The group contribution method developed by Hoftyzer and Van Krevelen was used to determine three solubility parameters: $\delta_{\mathrm{d}}, \delta_{\mathrm{p}}$, and $\delta_{\mathrm{h}}$, representing polymer dispersion, polar, and hydrogen bond interactions in the system, respectively. ${ }^{43}$

$$
\delta_{\text {TOTAL }}^{2}=\delta_{D}^{2}+\delta_{P}^{2}+\delta_{H}^{2}
$$

Tables 7.3 and $7.10^{43}$ were used to calculate $\delta_{\mathrm{d}}, \delta_{\mathrm{p}}, \delta_{\mathrm{h}}$ based on drug, lipid, and polymer major chemical structure groups. It should be noted that structural information for P90G is proprietary and its parameters were determined from the standard phosphatidylcholine structure discussed above. Thus, true P90G parameters may be different from those calculated.

\section{Cellular Uptake}

To enable visualization, coumarin-6 fluorescent reporter $(10 \mu \mathrm{L}, 1 \mathrm{mg} / \mathrm{mL})$ was co-encapsulated with lutein $(5$ $\mu \mathrm{L}, 1 \mathrm{mg} / \mathrm{mL}$ ) in delivery vehicles. Cellular uptake of co-loaded coumarin-6 and lutein P90G and PCL-PEO micelles was evaluated in the premalignant oral cell phenotype, SCC 83 cells. SCC 83 cells are a patient-derived cell line that was subsequently shown to have pre-malignant characteristics. ${ }^{44,45}$ The Ohio State University (OSU) Institutional Biosafety Committee (IBC) is responsible for reviewing research and providing guidance regarding the proper acquisition, handling, transfer, and disposal of potentially hazardous or regulated biological materials, including mammalian cell lines. The current studies were approved by the IBC under protocol 2016R00000011AM2: Models of Multistep Carcinogenesis, Prevention, and Therapeutics.

PS-PEO was not evaluated because of its low encapsulation efficiency. Cells were cultured in 24 well plates (in triplicate) to $\sim 6080 \%$ confluency and treated with $500 \mu \mathrm{L}$ micelles (post-lyophilization) re-suspended in culture media (Dulbecco's Minimum Essential Media, DMEM, $5 \%$ FBS, L-Glutamine, antibiotic-antimycotic). At designated time points $(0,5,15,30$, and 90 minutes), cells were rinsed with $1 \mathrm{x}$ phosphate buffered saline (PBS) and stained with Hoechst 33,342 to observe nuclei (Thermo Fisher, cat. no. H3570). Confocal images were taken at the same intensity at 20x magnification for each time point. DAPI and FITC channels were assigned to Hoescht and coumarin-6 reporters (respectively) and combined in ImageJ to visualize micelle cellular uptake over time.

\section{Statistics}

JMP Pro 14 software (SAS Institute Inc., Cary, NC, USA) was used to conduct statistical analysis. Because of the logarithmic nature of the particle size distribution data, the non-parametric Wilcoxon-Rank Sum test was used. The Student's $t$-test was used to evaluate the statistical significance of encapsulation efficiency between the two different synthesis processes. p-values $<0.05$ were considered statistically significant.

\section{Results and Discussion Micelle Particle Size and Morphology}

The primary goal of this work was to compare two different manufacturing processes: batch II sonication, which is thermodynamically controlled, ${ }^{33}$ and EM-NP, which is 
kinetically controlled, to each other across a range of delivery vehicle designs. Lutein-encapsulating micelles were formed via probe sonication or via EM-NP for P90G, PS-b-PEO, and PCL-b-PEO amphiphiles. To identify effects of synthesis method on particle size and morphology, loaded and empty micelles were evaluated using TEM (Figures 4 and 5). Size histograms generated from
TEM data were then fitted to a log normal three parameter distribution, where $\mu$ and $\sigma$ were extracted as the mean size and polydispersity (PD), respectively (Table 1). Particle size and distribution are critically linked to biodistribution and ability to cross cellular membranes. ${ }^{46,47}$ For these reasons, we desired spherical micelles $<100 \mathrm{~nm}$ in diameter with narrow size distributions. Generally, all
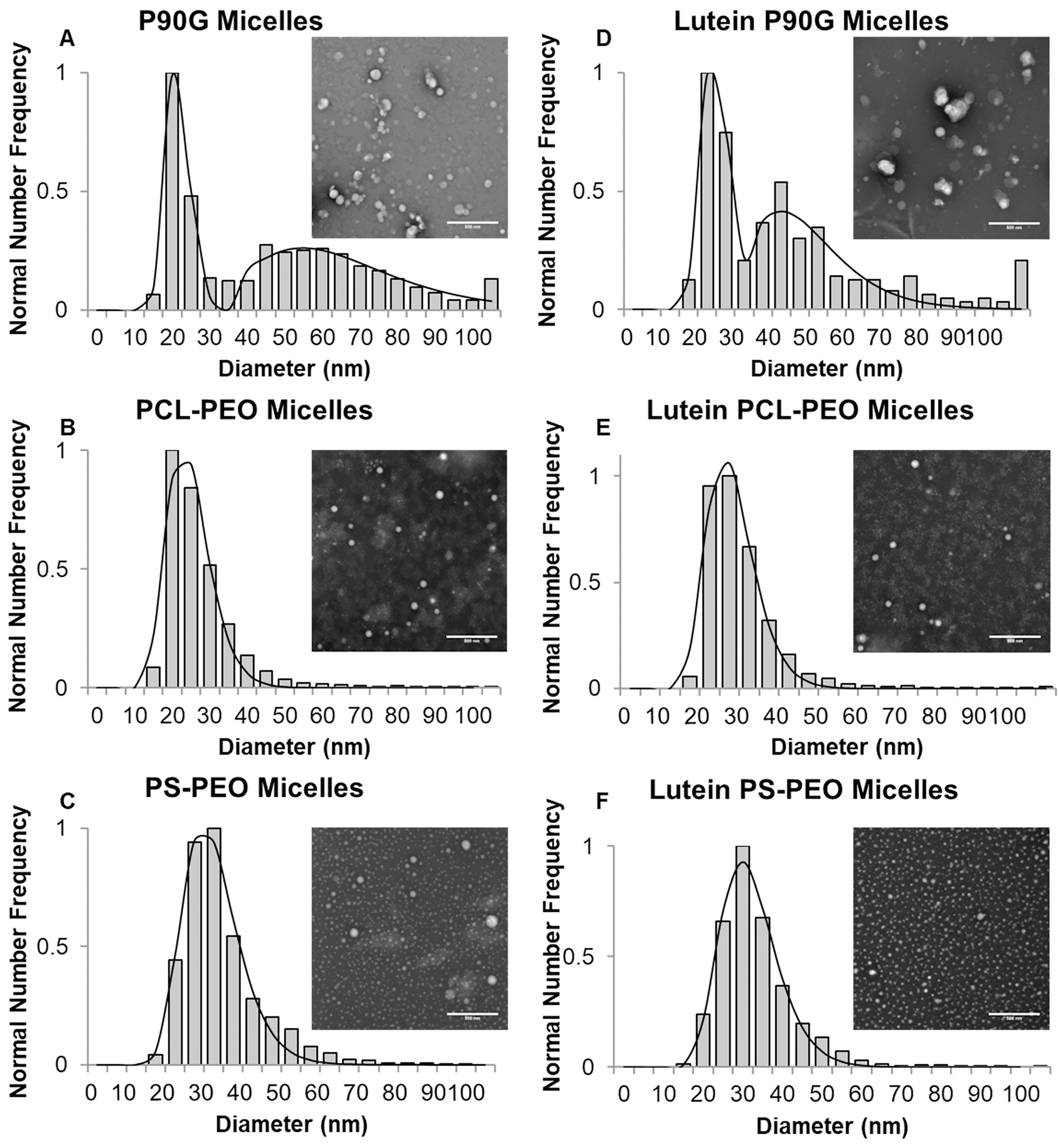

Figure 4 Particle size distribution and TEM imaging of unloaded $(\mathbf{A}-\mathbf{C})$ and lutein-loaded $(\mathbf{D}-\mathbf{F})$ micelles via II sonication. Scale bar $=500 \mathrm{~nm}$. 

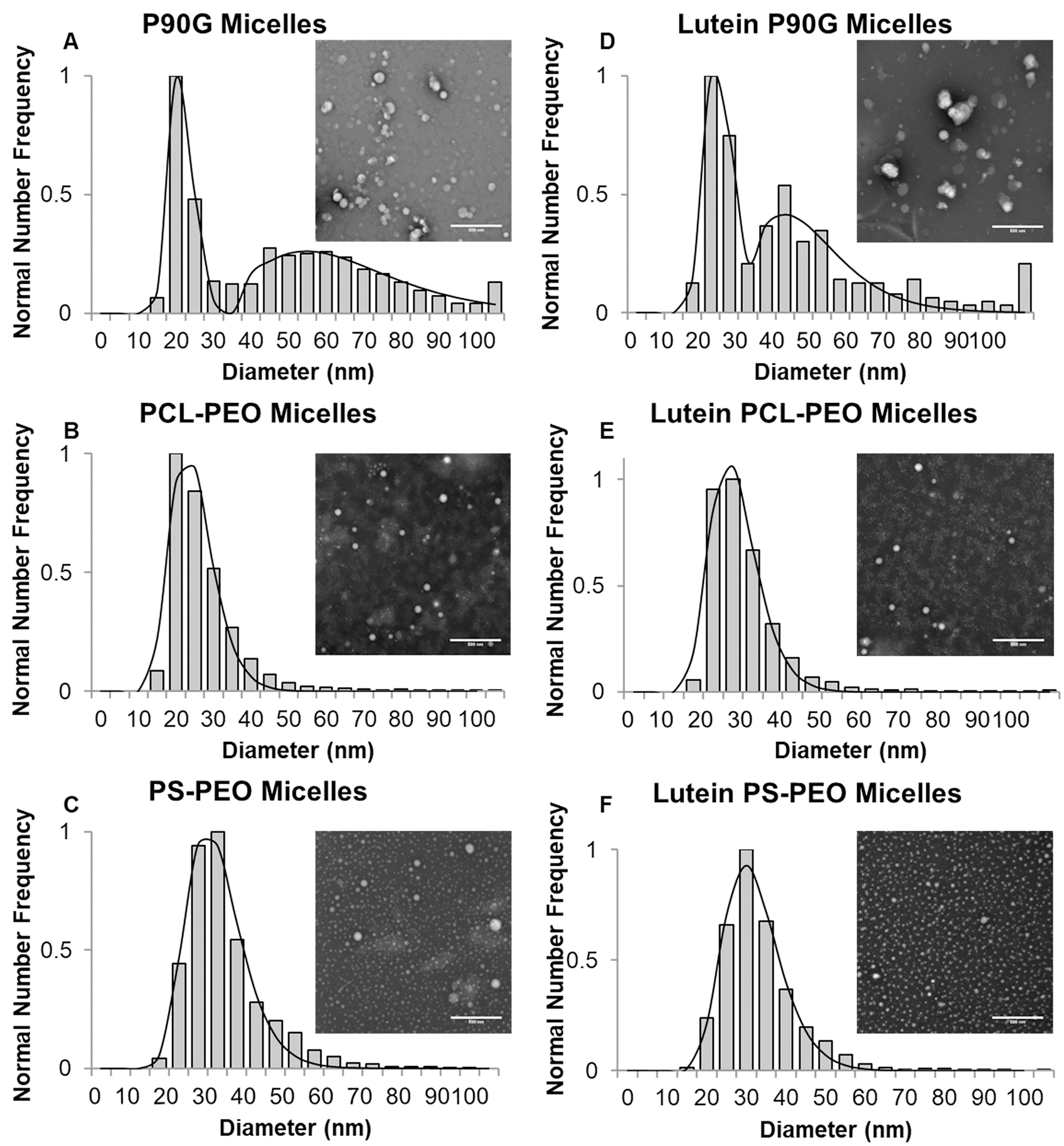

Figure 5 Particle size distribution and TEM imaging of unloaded $(\mathbf{A}-\mathbf{C})$ and lutein-loaded (D-F) micelles via EM-NP. Scale bar $=500 \mathrm{~nm}$.

systems yielded particles, but with varying morphology. Additionally, all vehicles experienced a slight increase in diameter with lutein addition, which suggests lutein encapsulation. ${ }^{41}$ Particle diameter increase is characteristic of drug addition to the nanoparticle and is commonly associated with evidence of encapsulation. However, there is no expected correlation between loaded carrier size among different systems and encapsulation efficiency, as final carrier size is dictated by amphiphile geometry and size.

In addition, statistical analysis identified a significant difference in size between the two methods of synthesis. Comparing II sonication to the scalable EM-NP processes, particles produced via II sonication were generally the 
Table I Particle Size and Polydispersity of Unloaded and Lutein-Loaded P90G, PCLPEO and PSPEO Micelles Synthesized via II Sonication and EM-NP

\begin{tabular}{|c|c|c|c|c|c|c|c|c|}
\hline \multicolumn{9}{|c|}{ Particle Diameter (nm) via Interfacial Instability (II) Sonication } \\
\hline & \multicolumn{2}{|l|}{ P90G } & \multicolumn{2}{|c|}{ P90G-Lut } & \multirow[t]{2}{*}{ PCLPEO } & \multirow[t]{2}{*}{ PCLPEO-Lut } & \multirow[t]{2}{*}{ PSPEO } & \multirow[t]{2}{*}{ PSPEO-Lut } \\
\hline & Peak I & Peak 2 & Peak I & Peak 2 & & & & \\
\hline Mean & 21.6 & 64.6 & 22.6 & 45.6 & 24.8 & 25.8 & 30.0 & 32.1 \\
\hline$+\operatorname{dev}^{\mathrm{a}}$ & +3.5 & +25.4 & +4.4 & +15.5 & +6.7 & +7.1 & +8.5 & +8.3 \\
\hline$-\operatorname{dev}^{b}$ & -3.0 & -18.2 & -3.7 & -11.6 & -5.3 & -5.6 & -6.6 & -6.6 \\
\hline $\mathrm{PD}_{\text {eff }}^{\mathrm{c}}$ & 0.151 & 0.333 & 0.178 & 0.294 & 0.239 & 0.244 & 0.249 & 0.231 \\
\hline \multicolumn{9}{|c|}{ Particle Diameter $(\mathrm{nm})$ via EM-NP } \\
\hline & \multicolumn{2}{|l|}{ P90G } & \multicolumn{2}{|c|}{ P90G-Lut } & \multirow[t]{2}{*}{ PCLPEO } & \multirow[t]{2}{*}{ PCLPEO-Lut } & \multirow[t]{2}{*}{ PSPEO } & \multirow[t]{2}{*}{ PSPEO-Lut } \\
\hline & Peak I & Peak 2 & Peak I & Peak 2 & & & & \\
\hline Mean & 25.8 & - & 23.0 & - & 24.5 & 24.7 & 19.7 & 26.3 \\
\hline$+\operatorname{dev}^{\mathrm{a}}$ & +7.68 & - & +5.2 & - & +9.0 & +8.6 & +4.8 & +8.8 \\
\hline$-d e v^{b}$ & -6.0 & - & -4.2 & - & -6.6 & -6.4 & -3.9 & -6.6 \\
\hline $\mathrm{PD}_{\text {eff }}{ }^{\mathrm{c}}$ & 0.263 & - & 0.204 & - & 0.315 & 0.300 & 0.220 & 0.290 \\
\hline
\end{tabular}

Notes: ${ }^{\mathrm{a}, \mathrm{b}}$ Standard deviations of the positive and negative sides of the distribution, respectively. ${ }^{\mathrm{c}}$ Effective polydispersity.

Abbreviations: P90G, PHOSPHOLIPON 90G ${ }^{\circledR}$; P90G-Lut, lutein-loaded P90G carriers; PCLPEO, polycaprolactone-poly (ethylene oxide) carriers; PCLPEO-Lut, luteinloaded PCLPEO carriers; PSPEO, polystyrene-poly (ethylene oxide) carriers; PSPEO-Lut, lutein-loaded PSPEO carriers.

same size or larger than those produced via EM-NP and less uniform in morphology. PS-b-PEO NPs showed a greater size increase than PCL-b-PEO NPs. However, the most striking difference occurred for the P90G samples. Both empty and lutein-loaded P90G micelles formed via II sonication were granular, aggregated, and characterized by a non-uniform, biphasic size distribution (determined by two major peaks for particle diameter mode). (Figure 4A and D). Also, unlike polymer micelle systems, P90G II sonication was the only system that exhibited a significant number of particles with diameters $>100 \mathrm{~nm}$. In contrast to II sonication, similar morphology and size distribution was observed for all systems made via EM-NP (Figure 5). P90G particles synthesized via EM-NP (Figure 5A and D) presented no particles $>100 \mathrm{~nm}$. These morphological differences may be attributed to differences in aggregation kinetics between P90G, which has two hydrocarbon tail chains, versus the single-chain structures of PSPEO and PCLPEO polymers.

Regarding differences between the two processes, II sonication is a thermodynamically driven process by which particle formation is dictated by the lowest energy state between polymer and drug. Alternatively, EM-NP is a kinetically-driven process for which particle size and formation are dictated by nucleation and growth time. ${ }^{48}$ Further EM-NP has a much lower organic/aqueous solvent ratio than traditional sonication approaches. Chain arrangement is dictated by rapid mixing and change in organic solvent concentration; promoting compact arrangement and reduced swelling that may explain the smaller diameters observed for some EM-NP particles versus II sonication. ${ }^{27,49}$ Particle uniformity is increased by rapid kinetics, which reduces particle growth time, particularly the ability of aggregates of either polymer or drug to form.

\section{Encapsulation Efficiency}

Noting the low aqueous affinity of hydrophobic encapsulants, drug release was not measured. Previously, we have observed virtually no release in PBS over 7 days and that release is "smart", occurring primarily as a result of endosomal rupture. ${ }^{41}$ Thus, this study focused on the effect of synthesis method on lutein encapsulation across the three delivery vehicles. II sonication processes uniformly resulted in lower encapsulation efficiencies than scalable EM-NP processes (Table 2), suggesting that the kinetically driven nature of EM-NP may allow for greater drug loading. ${ }^{27}$ This is similar to results reported for other scalable NP processes, such as flash nanoprecipitation. ${ }^{50}$ It has been suggested that the fast kinetics of nanoprecipitation processes can result in aggregation of drugs followed by polymer stabilization, which inherently increases encapsulation in the core compared to processes in which thermodynamic equilibrium is attained. 
Table 2 Encapsulation Efficiency (EE) of Lutein in Each System Synthesized via II Sonication and EM-NP

\begin{tabular}{|l|l|l|l|l|l|l|}
\hline \% Encapsulation of Lutein & \multicolumn{3}{l|}{ EMNP } \\
\hline & II Sonication & \multicolumn{2}{l|}{} \\
\cline { 2 - 7 } & P90G & PCL-PEO & PS-PEO & P90G* & PCL-PEO & PS-PEO \\
\hline Average \pm SE & $17.4 \pm 3.77$ & $9.86 \pm 1.24$ & $2.09 \pm 0.49$ & $55.6 \pm 3.25$ & $14.08 \pm 5.07$ & $4.46 \pm 0.94$ \\
\hline
\end{tabular}

Notes: ${ }^{a}$ Interfacial Instability Sonication, ${ }^{b}$ Electrohydrodynamic Mixing- Nanoprecipitation, SE = Standard Error, *EE significantly different between manufacturing systems $(p=0.0024)$.

Abbreviations: P90G, PHOSPHOLIPON 90G ${ }^{\circledR}$; P90G-Lut, lutein-loaded P90G carriers; PCLPEO, polycaprolactone-poly (ethylene oxide) carriers; PCLPEO-Lut, luteinloaded PCLPEO carriers; PSPEO, polystyrene-poly (ethylene oxide) carriers; PSPEO-Lut, lutein-loaded PSPEO carriers.

Further, lutein is susceptible to damage upon exposure to heat, light, and oxidizing agents. ${ }^{13,16,51}$ One main observation noted in samples formed via II sonication was increased temperature, which introduces the possibility of heat damage to lutein during nanoparticle synthesis. Additionally, the presence of PVA may have influenced lutein encapsulation. After resuspension of lyophilized II sonication samples in THF (to perform encapsulation efficiency measurements), samples often contained orangetinted PVA that did not dissolve, assumed to be PVAtrapped lutein. In contrast, the EM-NP utilized Tween 20 as a stabilization agent, which may have been more compatible with lutein encapsulants.

Comparing across polymer and lipid delivery vehicles, encapsulation of lutein was highest in P90G (55.6\%), followed by PCLPEO (14.08\%) and PSPEO (4.46\%) (Table 2). To understand these trends, Hansen solubility parameters (HSPs) $(\delta)^{43}$ were calculated for these systems. These parameters represent the cohesive energy of molecules present in the compound of interest (based on dispersion $\left(\delta_{\mathrm{d}}\right)$, polar groups $\left(\delta_{\mathrm{p}}\right)$ and hydrogen bonds $\left.\left(\delta_{\mathrm{h}}\right)\right)$ and are commonly used to determine polymer-solvent compatibility. Additionally, these parameters can be utilized to evaluate drug-polymer interactions, useful for describing experimental encapsulation data. ${ }^{43} \delta_{\mathrm{h}}$ is an important factor in this analysis because cohesive energy is largely dependent on polar groups and hydrogen bonding. ${ }^{52}$ Non-covalent interactions between hydrogen bonds and hydrophobic drug groups within the copolymer enhance hydrophobicity, creating stronger interaction between drug and polymer. ${ }^{52} \mathrm{~A}$ major weakness of this approach is that $\delta$ cannot be determined directly, therefore there is large variability in parameter values calculated and there are a number of methods to determine solubility parameters. Here, we use the group contribution method established by Hoftyzer and Van Krevelen. ${ }^{43}$ This method is considered more rigorous compared to others as it maintains a mean accuracy of roughly $10 \%$.

Solubility parameter analysis supports encapsulation results observed in both polymer micelle systems (Tables 3 and 4). $\delta_{\mathrm{h}}$ values of lutein, PS, and PCL are 8.47, 0.00, and 7.25 , respectively. The wide contrast between lutein and PS $\delta_{\mathrm{h}}$ values correlates with the PS polymer system having the lowest encapsulation efficiency observed in the experimental data. The difference between lutein and PCL $\delta_{\mathrm{h}}$ values is considerably lower $\left(\Delta \delta_{\mathrm{h}}=1.22\right)$ suggesting better solubility between the drug and polymer, but only a modest increase in EE (ie, $9.86 \%$ and $14.08 \%$ for II sonication and EM-NP, respectively) is observed over that of PS systems (ie, $2.09 \%$ and $4.46 \%$ for II sonication

Table 3 Hansen Solubility Parameters (HSPs $\left(\mathrm{MJ}^{3} \mathrm{~m}^{3}\right)^{1 / 2}$ ) of Lutein and Corresponding Hydrophobic and Hydrophilic Block Copolymer Segments, P90G, and Water; Calculated Using the Group Contribution Method

\begin{tabular}{|l|l|l|l|l|}
\hline Compound & $\boldsymbol{\delta}_{\mathbf{d}}$ & $\boldsymbol{\delta}_{\mathbf{p}}$ & $\boldsymbol{\delta}_{\mathbf{h}}$ & $\boldsymbol{\delta}_{\text {Total }}\left(\mathbf{M J j}_{\mathbf{m}} \mathbf{m}^{\mathbf{3}}\right)^{\mathbf{1 / 2}}$ \\
\hline Lutein & 15.24 & 1.80 & 8.47 & 17.53 \\
P90G & 17.35 & 9.83 & 7.30 & 21.97 \\
PCL & 18.30 & 12.30 & 7.25 & 23.21 \\
PS & 20.58 & 1.27 & 0.00 & 20.62 \\
PEO & 21.46 & 29.50 & 8.75 & 37.51 \\
Water & 18.50 & 16.00 & 42.30 & 47.81 \\
\hline
\end{tabular}

Abbreviations: $d$, dispersive; p, polarizing; and h, hydrogen bonding contributions; P90G, PHOSPHOLIPON 90G ${ }^{\circledR}$; PCL, polycaprolactone; PS, polystyrene; PEO, poly (ethylene oxide). 
Table 4 Change in $\delta$ Values Between Lutein and P90G or Hydrophobic Copolymer Blocks

\begin{tabular}{|c|c|c|c|c|c|c|c|c|c|}
\hline \multirow[t]{2}{*}{ Polymer } & \multicolumn{3}{|l|}{$\Delta \delta \mathrm{d}$} & \multicolumn{3}{|l|}{$\Delta \delta p$} & \multicolumn{3}{|l|}{$\Delta \delta \mathrm{h}$} \\
\hline & P90G & PCL & PS & P90G & PCL & PS & P90G & PCL & PS \\
\hline Lutein & -2.10 & -3.05 & -5.34 & -8.04 & $-|0.5|$ & 0.52 & 1.18 & 1.22 & 8.47 \\
\hline
\end{tabular}

Abbreviations: d, dispersive; p, polarizing; and h, hydrogen bonding contributions; P90G, PHOSPHOLIPON 90G ${ }^{\circledR}$; PCL, polycaprolactone; PS, polystyrene; PEO, poly (ethylene oxide).

and EM-NP, respectively). The P90G $\delta_{\mathrm{h}}$ value is only modestly higher than that of PCL (7.30 vs 7.25 for a $\Delta \delta_{\mathrm{h}}$ $=1.18$ ), yet encapsulation efficiencies of as much as $55 \%$ were observed. Thus, the P90G system had the greatest drug - polymer compatibility.

Although the general EE trend predicted by HSPs is observed, the dramatic increase for P90G was unexpected. It should be noted that P90G HSP values were based on the hydrophilic (choline head) block of the BCP, since the hydrophobic portion is proprietary, which almost certainly contributes to results. Further, the influence of the PEO block in PSPEO and PCLPEO BCPs should be considered. $\delta_{\mathrm{h}}$ values of lutein and PEO are comparable (8.47 and 8.75, respectively). Even though PEO is the hydrophilic block of these systems, it is possible that drug associated with the hydrophilic block only to be rapidly desorbed during washing and purification processes prior to $\mathrm{EE}$ quantification. Thus, although systems have widespread use in the nanoprecipitation and polymer micelle community, $^{33,53}$ their suitability for drug encapsulation depends heavily on chemical compatibility with the specific drug to be encapsulated. Based on the high EE of lutein in P90G, it is likely that the P90G hydrophobic core and the choline hydrophobic corona work in a distinctly unique way to provide an ideal soluble environment for lutein.

Whereas HSPs provide some basis for predicting and understanding drug - polymer interactions, the Hansen solubility parameter distance $(\mathrm{Ra})$ may provide a better measure of interactions. Ra considers molecular interactions in three-dimensional space ${ }^{54}$ and is calculated by the following equation:
$R a=\sqrt{ }\left(4\left[\left(\delta_{D 1}-\delta_{D 2}\right)\right]^{2}+\left[\left(\delta_{P 1}-\delta_{P 2}\right)\right]^{2}+\left[\left(\delta_{H 1}-\delta_{H 2}\right)\right]^{2}\right.$

Smaller Ra values (the distance between molecular solubility spheres) equate to greater compatibility. Based on calculated Ra values (Table 5), compatibility trends reflect predictions of HSPs and experimental observations: lutein is most compatible with P90G followed by PCL then PS, PEO, and being least soluble in water. This data is analogous to EE results and makes a strong case for lutein's EE and affinity in P90G. PCL and PS Ra values were similar (12.22 and 13.64, respectively), and unlike HSP $\Delta \delta_{\mathrm{h}}$ values, more closely predicted observed experimental EE trends. To further analysis of lutein-polymer interactions, the Flory-Higgins parameter $\left(\mathrm{X}_{\mathrm{sp}}\right)$ was also evaluated. This parameter has been successful in predicting drug solubility by assessing drug molecule interactions with polymer chains, ${ }^{55}$ and effectively adds a molar volume correction to HSP and Ra equations.

$$
\mathrm{X}_{s p}=\frac{R a^{2} v_{s}}{R T}
$$

where $v_{\mathrm{s}}$ is the molar volume of the drug, $\mathrm{R}$ is the gas constant, and $\mathrm{T}$ is temperature in Kelvin. Thus, low $\chi \mathrm{X}_{\mathrm{sp}}$ reflects better polymer-molecule compatibility. From calculated $\mathrm{X}_{\mathrm{sp}}$ values, lutein is more compatible with P90G, followed by PCL, PS, PEO, and then water (Table 6). $\mathrm{X}_{\mathrm{sp}}$ results better reflect EE differences seen between the PCL and PS BCP systems with an 8 point difference in interaction values. PEO and water $X_{\mathrm{sp}}$ values (207.2 and 311.9) also suggest low lutein EE in PEO blocks and low solubility in the aqueous phase. Thus, of these parameter sets, Flory-Huggins and Hansen interaction spheres (Ra) were

Table 5 Hansen Solubility Parameter Distance $\left(\mathrm{Ra}\left(\mathrm{MJ} / \mathrm{m}^{3}\right) \mathrm{I} / 2\right)$ Values Between Lutein and BCPs and Water

\begin{tabular}{|c|c|c|c|c|c|}
\hline \multicolumn{6}{|c|}{$\operatorname{Ra}\left(M J / m^{3}\right)^{1 / 2}$} \\
\hline & PS & PCL & P90G & PEO & Water \\
\hline Lutein & 13.64 & 12.22 & 9.15 & 30.37 & 37.26 \\
\hline
\end{tabular}

Abbreviations: P90G, PHOSPHOLIPON 90G ${ }^{\circledR}$; PCL, polycaprolactone; PS, polystyrene; PEO, poly (ethylene oxide). 
Table 6 Flory-Higgins Interaction Parameter $\left(\mathrm{X}_{\mathrm{sp}}\right)$ Values of Lutein - Polymer and Lutein - Water Solutions

\begin{tabular}{|l|l|l|l|l|l|}
\hline$X_{\text {sp }}$ & PS & PCL & P90G & PEO & Water \\
\hline & 41.78 & 33.53 & 18.81 & 207.20 & 311.96 \\
\hline Lutein & P &
\end{tabular}

Abbreviations: P90G, PHOSPHOLIPON 90G ${ }^{\circledR}$; PCL, polycaprolactone; PS, polystyrene; PEO, poly (ethylene oxide).

more predictive of EE than differences in Hansen $\delta_{\mathrm{h}}$ values.

\section{Cellular Uptake}

As a precursor to in vitro analysis of lutein as an oral cancer chemopreventative, we observed cellular uptake of lutein-P90G and lutein-PCLPEO micelles in premalignant oral squamous epithelial cells (SCC83). ${ }^{44,45}$ [Because of low encapsulation efficiency, PSPEO micelles were not further analyzed.] To permit observation, lutein was coencapsulated with a fluorescent dye, coumarin-6, and imaged over 90 minutes via time-lapse confocal microscopy (Figure 6). Previously, we reported trafficking of coumarin-only micelles using this approach, showing that they initially exhibit punctate signal, indicating individual micelles, that becomes diffuse cytoplasmic signal over time, most likely resulting from micelles rupturing in the endosomal environment. ${ }^{41}$ For P90G micelles, coumarin-6 signal could be detected along the cell membrane at 15 minutes (Figure 6C). Gradual uptake was observed by 30 minutes, as the signal intensified. Micelles exhibited a sustained presence in cells up to 90 minutes after application, eventually filling the cytoplasm surrounding the cell nucleus (Figure 6D and E). This suggests endocytosis as a mechanism by which P90G micelles are internalized and trafficked through the lysosomal cycle. Upon reaching the
0 minutes
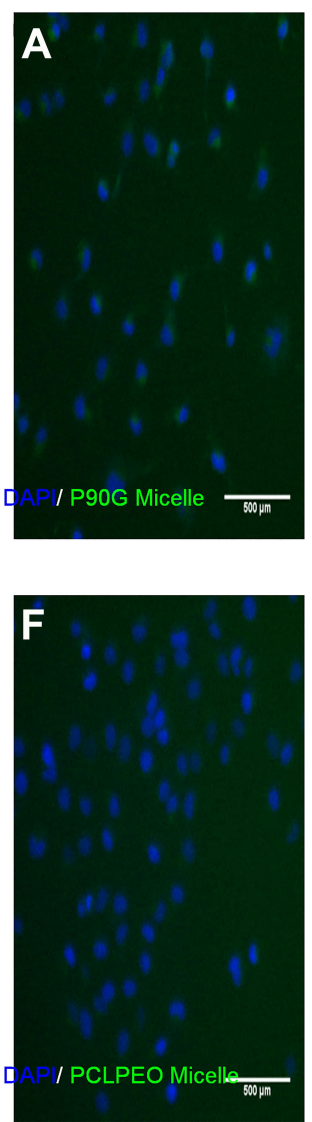

5 minutes
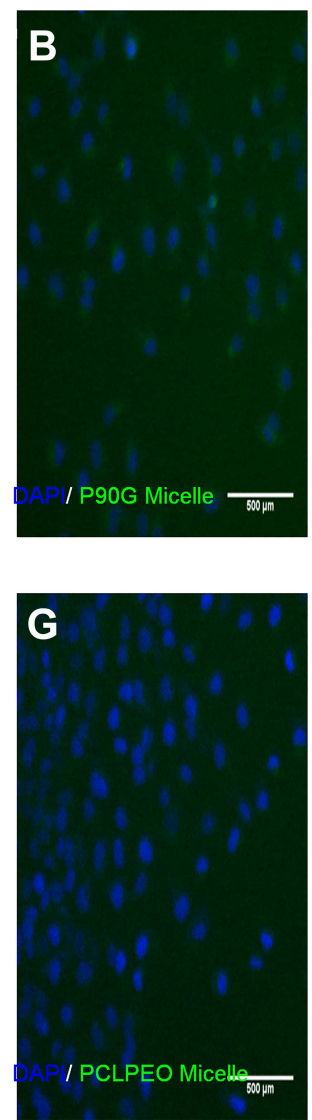

15 minutes
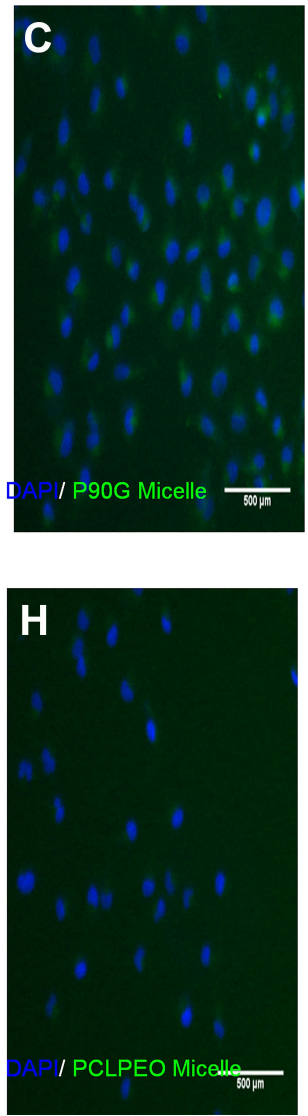

30 minutes
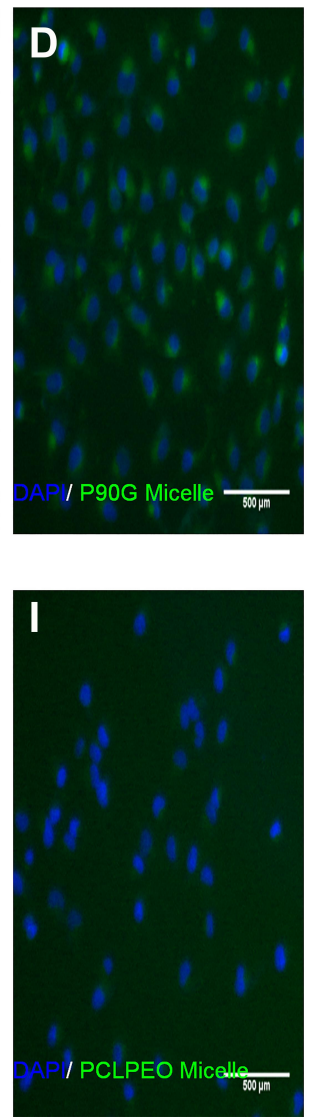

90 minutes

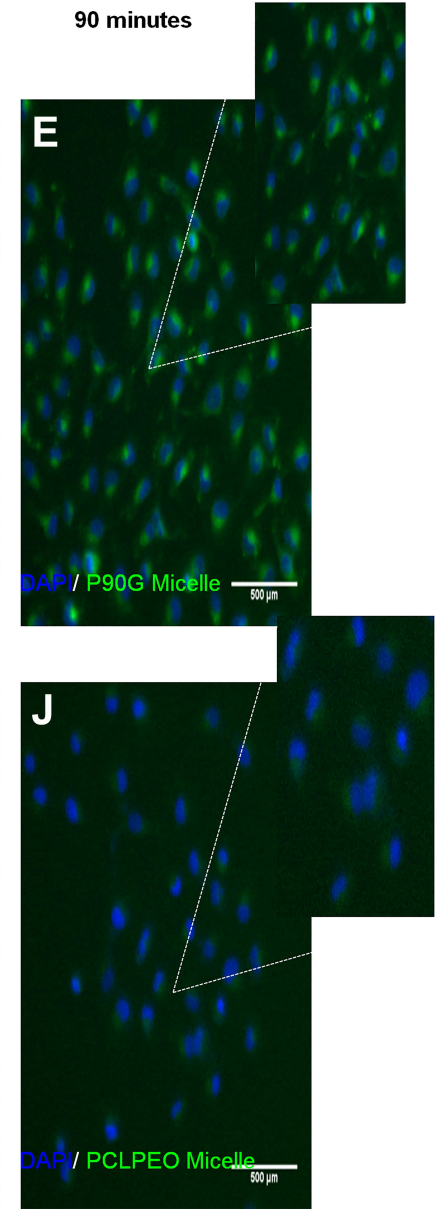

Figure 6 Cellular uptake of co-loaded coumarin-6 and lutein P90G micelles (A-E) and PCLPEO micelles (F-J) in SCC83 human oral epithelial cells. Scale bar = 500 micron. 
lysosome, reduced $\mathrm{pH}$, proteolysis or both, reduces micelle integrity, resulting in drug/coumarin release throughout the cytoplasm.

In contrast, coumarin-6 signal was poorly detected for PCLPEO micelles throughout the time course observed, with only faint detection at 90 minutes (Figure 6FJ). The amount of lutein and coumarin-6 used during synthesis were kept the same for each particle system; thus, the data suggest that lutein-P90G micelles more successfully deliver their contents to SCC83 cells than lutein-PCLPEO micelles. These observations may result from two factors: varying EE for coumarin-6 in PCLPEO micelles or differing physicochemical properties between the two vehicle materials. Size, shape, surface charge, and vehicle stiffness $^{56}$ are among the factors that impact cellular uptake. These features dictate cell membrane interactions by altering membrane energy dynamics to favor or disrupt particle internalization. ${ }^{57}$ Since vehicle size and shape are similar, particle chemical properties are strong possible contributors in varying cellular uptake. In studies evaluating particle transport in normal and carcinogenic cells, PCLPEO micelles initially experience slow uptake and do not exhibit a distinct presence in cells until 2-3 hours post-incubation. ${ }^{58,59}$ Additionally, whereas the total net charge of P90G head groups is neutral, lipid fusion and membrane association, known as "lipid-raft effect" 60 elicit a possible endocytosis pathway for rapid cellular uptake. Additionally, we recognize that the addition of coumarin-6 may alter nanoparticle structure and lutein EE by influencing drug-drug and drug-polymer interactions, which could influence these results.

\section{Conclusion}

In this study, we synthesized three micelle delivery systems encapsulating lutein using two methods. Size distribution, particle morphology, encapsulation efficiency, and cellular uptake in premalignant oral cells (SCC83) were evaluated for each system and method. Whereas a difference in particle morphology was not observed for polymer micelle systems (ie, PSPEO and PCLPEO) between II sonication and EM-NP synthesis methods, EM-NP generally provided more uniform morphology and tighter size distribution for lipid micelle samples (eg, P90G) compared to standard sonication processes. Further, EM-NP processing yielded higher lutein encapsulation efficiency for all three systems compared to II sonication, and generally produced smaller or similarly sized particles. These results were best predicted by the use of Flory-Huggins interaction parameters or Hansen spheres. These data support previous observations ${ }^{61}$ that scalable nanoprecipitation processes offer significant advantages in nanoparticle processing for drug delivery applications. The kinetically driven nature of EM-NP synthesis may allow for higher drug loading while maintaining small particle size and narrow distribution. Further, this technique could enable transition to commercial production and scale-up. The primary goal of this work was not to identify a specific optimal carrier, but rather to compare systems of carriers in different manufacturing schemes. However, among the three delivery vehicles, P90G had the highest lutein encapsulation efficiency and delivered lutein to target cells within 15 minutes of application. These outcomes most likely result from high drug-lipid solubility and the biomimetic structure of P90G lipids. Additional studies should focus on continued characterization of this system, including its toxicity, biodistribution, and cell cycle and apoptosis effects. In particular, animal work could provide additional information on ability of these carriers to cross oral mucosal barriers or gastrointestinal trafficking that would be crucial for oral formulations. P90G is an attractive candidate for lutein delivery in the food industry because of its plant-derived nature. ${ }^{39}$ These qualities suggest P90G as a beneficial candidate for future lutein in vitro delivery research and clinical translation for oral cancer prevention.

\section{Acknowledgments}

The authors gratefully acknowledge funding from NSF CMMI-1344567 (KHL, JOW), T32DE014320 (P.I. John

F. Sheridan) Comprehensive Training In Oral And Craniofacial Sciences, NIH NIDCR, Pre-doctoral Fellowship (LEC), NIH grants: U01CA188250, Interactive Omics: Black Raspberry Metabolites and the Oral Microbiome in Smokers, PI: Christopher M. Weghorst, The Ohio State University and P30CA016058, Cancer Center Support Grant, PI: Raphael E. Pollock, The Ohio State University, Comprehensive Cancer Center. This work was supported in part by The Ohio State University Institute for Materials Research, the OSUCCC Genomics Shared Resource, OSUCCC Analytical Cytometry Shared Resource, and OSUCCC Nutrient and Phytochemical Analytics Shared Resource. We would like to thank Yixiao Cui for her assistance with cell imaging, Prof. Barbara E. Wyslouzil for helpful discussions on the EMNP process, and Drs. Jennifer Ahn-Jarvis and Chureeporn 
Chitchumroonchokchai for guidance on black raspberryderived bioactive selection.

\section{Disclosure}

Thomas J. Knobloch reports grants from The Ohio State University College of Dentistry, during the conduct of the study. The authors report no other potential conflicts of interest in this work. This manuscript is based in part on work published in the thesis of Lauren Cosby. ${ }^{62}$

\section{References}

1. Eisenhauer B, Natoli S, Liew G, Flood VM. Lutein and zeaxanthinfood sources, bioavailability and dietary variety in age-related macular degeneration protection. Nutrients. 2017;9(2):120. doi:10.3390/ nu9020120

2. Trichopoulou A, Bamia C, Trichopoulos D. Anatomy of health effects of mediterranean diet: greek EPIC prospective cohort study. BMJ. 2009;338:b2337. Doi:10.1136/bmj.b2337

3. Liu RH. Health-promoting components of fruits and vegetables in the diet. Adv Nutr. 2013;4(3):384S392S. doi:10.3945/an.112.003517

4. Dorgan JF, Sowell A, Swanson CA, et al. Relationships of serum carotenoids, retinol, $\alpha$-tocopherol, and selenium with breast cancer risk: results from a prospective study in Columbia, Missouri (United States). Cancer Causes Control. 1998;9(1):89-97. doi:10.1023/ A:1008857521992

5. Krinsky NI, Johnson EJ. Carotenoid actions and their relation to health and disease. Mol Aspects Med. 2005;26(6):459-516. doi:10.1016/j.mam.2005.10.001

6. Rao AV, Rao LG. Carotenoids and human health. Pharmacol Res. 2007;55(3):207-216. doi:10.1016/j.phrs.2007.01.012

7. Rafi MM, Kanakasabai S, Gokarn SV, Krueger EG, Bright JJ. Dietary lutein modulates growth and survival genes in prostate cancer cells. $J$ Med Food. 2015;18(2):173-181. doi:10.1089/jmf.2014.0003

8. Cheng HC, Chien H, Liao CH, Yang YY, Huang SY. Carotenoids suppress proliferating cell nuclear antigen and cyclin D1 expression in oral carcinogenic models. J Nutr Biochem. 2007;18(10):667-675. doi:10.1016/j.jnutbio.2006.10.010

9. Pan P, Skaer CW, Stirdivant SM, et al. Beneficial regulation of metabolic profiles by black raspberries in human colorectal cancer patients. Cancer Prev Res. 2015;8(8):743-750. doi:10.1158/19406207.CAPR-15-0065

10. Zikri NN, Riedl KM, Wang LS, Lechner J, Schwartz SJ, Stoner GD. Black raspberry components inhibit proliferation, induce apoptosis, and modulate gene expression in rat esophageal epithelial cells. Nutr Cancer. 2009;61(6):816-826. doi:10.1080/01635580903285148

11. Peiffer DS, Wang LS, Zimmerman NP, et al. Dietary consumption of black raspberries or their anthocyanin constituents alters innate immune cell trafficking in esophageal cancer. Cancer Immunol Res. 2016;4(1):72-82. doi:10.1158/2326-6066.CIR-15-0091

12. Wani TA, Shah AG, Wani SM, et al. Suitability of different food grade materials for the encapsulation of some functional foods well reported for their advantages and susceptibility. Crit Rev Food Sci Nutr. 2016;56(15):2431-2454. doi:10.1080/10408398.2013.845814

13. Boon CS, McClements DJ, Weiss J, Decker EA. Factors influencing the chemical stability of carotenoids in foods. Crit Rev Food Sci Nutr. 2010;50(6):515-532.

14. Losso J, Khachatryan A, Ogawa M, Godber J, Shih F. Random centroid optimization of phosphatidylglycerol stabilized luteinenriched oil-in-water emulsions at acidic pH. Food Chem. 2005;92 (4):737-744. doi:10.1016/j.foodchem.2004.12.029
15. Amar I, Aserin A, Garti N. Solubilization patterns of lutein and lutein esters in food grade nonionic microemulsions. J Agric Food Chem. 2003;51(16):4775-4781. doi:10.1021/jf026222t

16. Weigel F, Weiss J, Decker EA, McClements DJ. Lutein-enriched emulsion-based delivery systems: influence of emulsifiers and antioxidants on physical and chemical stability. Food Chem. 2018;242:395-403. doi:10.1016/j.foodchem.2017.09.060

17. Mora-Gutierrez A, Attaie R, Nunez de Gonzalez MT, Jung Y, Woldesenbet S, Marquez SA. Complexes of lutein with bovine and caprine caseins and their impact on lutein chemical stability in emulsion systems: effect of arabinogalactan. J Dairy Sci. 2018;101 (1):18-27. doi:10.3168/jds.2017-13105

18. Sato Y, Joumura T, Nashimoto S, et al. Enhancement of lymphatic transport of lutein by oral administration of a solid dispersion and a self-microemulsifying drug delivery system. Eur J Pharm Biopharm. 2018;127:171-176. doi:10.1016/j.ejpb.2018.02.013

19. Li S, Wang C, Fu X, et al. Encapsulation of lutein into swelled cornstarch granules: structure, stability and in vitro digestion. Food Chem. 2018;268:362-368. doi:10.1016/j.foodchem.2018.06.078

20. Taylor P. Ostwald ripening in emulsions. Adv Colloid Interface Sci. 1998;75(2):107-163. doi:10.1016/S0001-8686(98)00035-9

21. Singh Y, Meher JG, Raval K, et al. Nanoemulsion: concepts, development and applications in drug delivery. $J$ Control Release. 2017;252:28-49.

22. Dickinson E. Biopolymer-based particles as stabilizing agents for emulsions and foams. Food Hydrocoll. 2017;68:219-231. doi:10. 1016/j.foodhyd.2016.06.024

23. McClements DJ, Gumus CE. Natural emulsifiers - Biosurfactants, phospholipids, biopolymers, and colloidal particles: molecular and physicochemical basis of functional performance. Adv Colloid Interface Sci. 2016;234:3-26. doi:10.1016/j.cis.2016.03.002

24. Rapoport N, Gupta R, Kim YS, O’Neill BE. Polymeric micelles and nanoemulsions as tumor-targeted drug carriers: insight through intravital imaging. J Control Release. 2015;206:153-160. doi:10.1016/j. jconrel.2015.03.010

25. Zhang S, Gao H, Bao G. Physical principles of nanoparticle cellular endocytosis. ACS Nano. 2015;9(9):8655-8671.

26. Pagels RF, Prud'homme RK. Polymeric nanoparticles and microparticles for the delivery of peptides, biologics, and soluble therapeutics. $J$ Control Release. 2015;219:519-535. doi:10.1016/j.jconrel.2015.09.001

27. Lee KH, Yang G, Wyslouzil B, Winter J. Electrohydrodynamic mixing-mediated nanoprecipitation for polymer nanoparticle synthesis. ACS Applied Polymer Materials. 2019;1(4):691-700. doi:10.1021/ acsapm.8b00206

28. Han J, Zhu Z, Qian H, et al. A simple confined impingement jets mixer for flash nanoprecipitation. J Pharm Sci. 2012;101(10):40184023. doi:10.1002/jps.23259

29. Liu Y, Tong Z, Prud'homme RK. Stabilized polymeric nanoparticles for controlled and efficient release of bifenthrin. Pest Manag Sci. 2008;64(8):808-812. doi:10.1002/ps.1566

30. Duong AD, Ruan G, Mahajan K, Winter JO, Wyslouzil BE. Scalable, semicontinuous production of micelles encapsulating nanoparticles via electrospray. Langmuir. 2014;30(14):3939-3948. doi:10.1021/ la404679r

31. Souva MS, Nabar GM, Winter JO, Wyslouzil BE. Morphology of block copolymer micelles formed via electrospray enabled interfacial instability. J Colloid Interface Sci. 2018;512:411-418. doi:10.1016/j. jcis.2017.10.087

32. Lu Y, Chowdhury D, Vladisavljević GT, Koutroumanis K, Georgiadou S. Production of fluconazole-Loaded polymeric micelles using membrane and microfluidic dispersion devices. Membranes. 2016;6(2):29. doi:10.3390/membranes6020029

33. Zhu JT, Hayward RC. Spontaneous generation of amphiphilic block copolymer micelles with multiple morphologies through interfacial instabilities. J Am Chem Soc. 2008;130(23):7496-7502. doi:10.1021/ ja801268e 
34. Nabar GM, Winter JO, Wyslouzil BE. Nanoparticle packing within block copolymer micelles prepared by the interfacial instability method. Soft Matter. 2018;14(17):3324-3335. doi:10.1039/C8SM00425K

35. Gindy ME, Panagiotopoulos AZ, Prud'homme RK. Composite block copolymer stabilized nanoparticles: simultaneous encapsulation of organic actives and inorganic nanostructures. Langmuir. 2008;24 (1):83-90. doi:10.1021/la702902b

36. Mumuni M, Attama AA, Kunle OO. Formulation in vitro and in vivo evaluation of SRMS-based heterolipid-templated homolipid delivery system for diclofenac sodium. Drug Deliv. 2016;23(3):917-925. doi:10.3109/10717544.2014.923062

37. Lindvall O, Kokaia Z, Bengzon J, Elmer E, Kokaia M. Neurotrophins and brain insults. Trends Neurosci. 1994;17(11):490-496. doi:10.10 16/0166-2236(94)90139-2

38. Seguin J, Brulle L, Boyer R, et al. Liposomal encapsulation of the natural flavonoid fisetin improves bioavailability and antitumor efficacy. Int J Pharm. 2013;444(12):146-154. doi:10.1016/j.ijpharm.20 13.01.050

39. Schubert MA, Müller-Goymann CC. Characterisation of surfacemodified solid lipid nanoparticles (SLN): influence of lecithin and nonionic emulsifier. Eur J Pharm Biopharm. 2005;61(12):77-86. doi:10.1016/j.ejpb.2005.03.006

40. van Hoogevest P. Review - An update on the use of oral phospholipid excipients. Eur J Pharm Sci. 2017;108:1-12. doi:10.1016/j.ejps.20 17.07 .008

41. Nabar GM, Mahajan KD, Calhoun MA, et al. Micelle-templated, poly (lactic-co-glycolic acid) nanoparticles for hydrophobic drug delivery. Int J Nanomedicine. 2018;13:351-366. doi:10.2147/IJN.S142079

42. Soares N. Relative solubility, stability, and absorptivity of lutein and b-carotene in organic solvents. J Agric Food Chem. 1992;40(3):431434. doi:10.1021/jf00015a013

43. Van Krevelen DWTNK. Cohesive properties and solubility. In: Properties of Polymers: Their Correlation with Chemical Structure; Their Numerical Estimation and Prediction from Additive Group Contributions. Elsevier; 2009:189-277.

44. Shuler C, Kurian P, French BT. Noncorrelative c-myc and ras oncogene expression in squamous cell carcinoma cells with tumorigenic potential. Teratog Carcinog Mutagen. 1990;10(1):53-65. doi:10.100 2/tcm. 1770100107

45. Milo GE, Shuler C, Kurian P, et al. Nontumorigenic squamous cell carcinoma line converted to tumorigenicity with methyl methanesulfonate without activation of HRAS or MYC. Proc Natl Acad Sci US A. 1990;87(4):1268-1272. doi:10.1073/pnas.87.4.1268

46. He C, Hu Y, Yin L, Tang C, Yin C. Effects of particle size and surface charge on cellular uptake and biodistribution of polymeric nanoparticles. Biomaterials. 2010;31(13):3657-3666. doi:10.1016/j. biomaterials.2010.01.065

47. Danaei M, Dehghankhold M, Ataei S, et al. Impact of particle size and polydispersity index on the clinical applications of lipidic nanocarrier systems. Pharmaceutics. 2018;10(2):57. doi:10.3390/ pharmaceutics 10020057

International Journal of Nanomedicine

\section{Publish your work in this journal}

The International Journal of Nanomedicine is an international, peerreviewed journal focusing on the application of nanotechnology in diagnostics, therapeutics, and drug delivery systems throughout the biomedical field. This journal is indexed on PubMed Central, MedLine, CAS, SciSearch ${ }^{\circledR}$, Current Contents ${ }^{\mathbb{R}} /$ Clinical Medicine,
48. D'Addio SM, Prud'homme RK. Controlling drug nanoparticle formation by rapid precipitation. Adv Drug Deliv Rev. 2011;63(6):417426. doi:10.1016/j.addr.2011.04.005

49. Kelley EG, Smart TP, Jackson AJ, Sullivan MO, Epps TH. Structural changes in block copolymer micelles induced by cosolvent mixtures. Soft Matter. 2011;7(15):7094-7102. doi:10.1039/c1sm05506b

50. Saad WS, Prud'homme RK. Principles of nanoparticle formation by flash nanoprecipitation. Nano Today. 2016;11(2):212-227. doi:10. 1016/j.nantod.2016.04.006

51. Subagio A, Wakaki H, Morita N. Stability of lutein and its myristate esters. Biosci Biotechnol Biochem. 1999;63(10):1784-1786. doi:10. $1271 / \mathrm{bbb} .63 .1784$

52. Zhang J, Li S, Li X, Li X, Zhu K. Morphology modulation of polymeric assemblies by guest drug molecules: TEM study and compatibility evaluation. Polymer. 2009;50(7):1778-1789. doi:10.10 16/j.polymer.2009.02.004

53. Johnson BK, Prud'homme RK. Flash NanoPrecipitation of organic actives and block copolymers using a confined impinging jets mixer. Aust J Chem. 2003;56(10):1021-1024. doi:10.1071/CH03115

54. Hansen CM. 50 Years with solubility parameters-past and future. Prog Org Coat. 2004;51(1):77-84. doi:10.1016/j.porgcoat.2004. 05.004

55. Latere Dwan'Isa JP, Rouxhet L, Preat V, Brewster ME, Arien A. Prediction of drug solubility in amphiphilic di-block copolymer micelles: the role of polymer-drug compatibility. Die Pharmazie Int J Pharm Sci. 2007;62(7):499-504.

56. Du Y, Fischer TZ, Lee LN, Lercher LD, Dreyfus CF. Regionally specific effects of BDNF on oligodendrocytes. Dev Neurosci. 2003;25(24):116-126. doi:10.1159/000072261

57. Adjei IM, Sharma B, Labhasetwar V. Nanoparticles: cellular uptake and cytotoxicity. Adv Exp Med Biol. 2014;811:73-91.

58. Figarol A, Gibot L, Golzio M, Lonetti B, Mingotaud AF, Rols MP. A journey from the endothelium to the tumor tissue: distinct behavior between PEO-PCL micelles and polymersomes nanocarriers. Drug Deliv. 2018;25(1):1766-1778. doi:10.1080/10717544.2018.1510064

59. Zhang Y, Chan HF, Leong KW. Advanced materials and processing for drug delivery: the past and the future. Adv Drug Deliv Rev. 2013;65(1):104-120. doi:10.1016/j.addr.2012.10.003

60. Costanzo M, Scolaro L, Berlier G, et al. Cell uptake and intracellular fate of phospholipidic manganese-based nanoparticles. Int J Pharm. 2016;508(12):83-91. doi:10.1016/j.ijpharm.2016.05.019

61. Johnson BK, Saad W, Prud'homme RK. Nanoprecipitation of pharmaceuticals using mixing and block copolymer stabilization. Polymeric Drug Delivery Ii. 2006;924:278-291.

62. Dissertation of Lauren Cosby. Preclinical delivery of fractionated black raspberry phytochemicals to oral epithelial cells using lipid and polymer nanoparticles; 2019. Available from: https://etd.ohio link.edu/!etd.send_file?accession=osu $1555521088604392 \&$ disposi tion=inline.
Journal Citation Reports/Science Edition, EMBase, Scopus and the Elsevier Bibliographic databases. The manuscript management system is completely online and includes a very quick and fair peer-review system, which is all easy to use. Visit http://www.dovepress.com/ system, which is all easy to use. Visit http://www.dovepress.
testimonials.php to read real quotes from published authors. 